\title{
Assimetria de Informação e Confiança em Interações Cooperativas
}

\section{Information Asymmetry and Trust in Cooperative Interactions}

\author{
Rosangela Violetti Bertolin* \\ Mestre em Administração pelo PPGAD/UFLA, Lavras/MG, Brasil. \\ Antônio Carlos dos Santos \\ Doutor em Administração pela USP. \\ Professor do DAE/UFLA, Lavras/MG, Brasil. \\ Juvêncio Braga de Lima \\ Doutor em Sociologia, Université de Montpellier, França. \\ Professor do DAE/UFLA, Lavras/MG, Brasil. \\ Marcelo José Braga \\ Pós- Doutorado em Economia Agrícola, UC Davis/Califórnia-EUA. \\ Professor do DER/UFV, Viçosa/MG, Brasil.
}

*Endereço: Caixa Postal 298, Barbacena/MG, 36200-970.

E-mail: rosangelabertolin@yahoo.com.br 


\title{
Resumo
}

O presente artigo é resultado de um estudo de caso cujo foco retratou a problemática da assimetria de informação em uma organização cooperativa. Após identificar aspectos da assimetria de informação existente no relacionamento agente (dirigentes) e principal (associados), procurou-se compreender seus efeitos nas transações e relações de confiança dos membros com a organização. A pesquisa foi feita com recurso a entrevistas, análise de documentos, registros em arquivos e observação não-participante. Empreendeu-se a Análise de Conteúdo sob a perspectiva qualitativa, buscando as significações da assimetria de informação e confiança por meio da análise das percepções e satisfações dos sujeitos investigados quanto ao gerenciamento de informações categorizadas tanto internas quanto externas à organização. Constatou-se existência de assimetrias nas informações de âmbito interno e externo entre dirigentes e associados. Esta assimetria traz efeitos negativos sobre a confiança dos associados em transacionar com a cooperativa, fatos que permitiram refletir sobre novas implicações para a análise teórica da agência aplicada a estas organizações.

Palavras-chave: assimetria; informação; cooperativa; confiança; agência.

\begin{abstract}
This paper results from a case study that shows the problem of information asymmetry in an agricultural marketing cooperative. After identifying aspects of the information asymmetry in the agent (managers) and principal (members) relationship, an attempt was made to understand the effects coming from transaction and trust relations from the members towards the cooperative business. The research is made by using interviews, document analysis, file records and non-participant observations. The Analysis of Content was undertaken based in the qualitative perspective, showing the significances of the information asymmetry and trust through the analysis of the perceptions and satisfactions of the investigated subjects referring to information management classified as internal and external information. The existence of high internal and external information asymmetries is verified among managers and members. Findings suggest that this asymmetry effects has a negative impact on members' trust in their transactions with the cooperative. The research explores new implications about agency theory analysis applied to cooperatives.
\end{abstract}

Key words: asymmetry; information; cooperative; trust; agency. 


\section{INTRODUÇÃO}

Incipiente na literatura organizacional, a temática da assimetria de informação tem-se concentrado nos estudos de análise econômica de mercados; a compreensão dos matizes desse fenômeno na perspectiva intra-organizacional ainda é tratada de maneira superficial.

Visando investigar a problemática da assimetria de informação nas relações de agente e principal, optou-se por conduzir o estudo junto a dirigentes e associados de uma organização cooperativa, buscando identificar a configuração dessa assimetria, bem como suas relações com a confiança dos associados em transacionar com a organização. Ressalta-se que a confiança tem sido apregoada como um dos pilares da cooperação, e a informação, como elemento antecessor e condicionante de ambas como abordado em Amodeo (1999); Blomqvist e Stahle (2000); Gambetta (2000); Good (2000); Lorenz (2000); Lorenzen (1998); Naves (1999); Zuurbier e Bremmers (1997).

Uma vez que a informação recebida pelos membros da cooperativa é controlada pelos dirigentes, estes, por sua vez, têm mais possibilidades de controlar o tipo e a profundidade da informação fornecida. Assim, a compreensão do fenômeno da assimetria de informação nesta relação mostra-se fundamental, pois o associado, na posição de principal, assume lugar central no funcionamento da organização em que a confiança é vital.

Nessa perspectiva, o presente artigo objetivou analisar a assimetria de informação na gestão organizacional cooperativa, buscando, especificamente, analisar o gerenciamento das informações direcionadas aos associados, as diferentes priorizações de associados e dirigentes acerca da valorização das informações, identificando-se os elementos que condicionam a assimetria de informação e os efeitos dela advindos, sobretudo na confiança dos membros em transacionar com a organização.

\section{Assimetria de Informação na Gestão Cooperativa}

A consideração de assimetria de informação no âmbito intra-organizacional, em especial nas relações entre os agentes e principais, desperta a atenção para uma análise da assimetria de informação numa perspectiva relacional. Em se 
tratando das organizações cooperativas, tal interesse recai, principalmente, sobre o poder de mando e de posse que esta forma organizacional confere aos membros associados.

Porque, em geral, o agente (dirigentes) detém o controle do tipo e da profundidade da informação fornecida ao principal (associados), a ocorrência de assimetrias informacionais é um pressuposto dado como verdadeiro. Considerandose que a informação assume preponderante papel na construção de confiança, pode-se depreender que a presença de assimetria de informação move forças na direção contrária.

Recentes pesquisas que abordam os principais problemas advindos das relações de agente e principal nas cooperativas enfatizam a importância da informação, pois é por meio de sua manipulação e ocultamento que se configuram diferentes níveis de conhecimento e ações comprometedoras de uma gestão transparente e eficiente, afetando sobremaneira os níveis de confiança e comprometimento, emergindo custos de monitoramento que tenderão a enfraquecer o relacionamento entre os pares (Hakelius, 1998; Nilsson, 2001). Nesse sentido, a concepção da existência de assimetrias informacionais coloca em questionamento as consequiências advindas desta possível realidade.

A assimetria de informação descreve o fenômeno segundo o qual alguns agentes econômicos têm mais informação do que sua contrapartida, moldando um cenário incerto e inseguro. Nessa concepção, o grau de incerteza pode assumir a forma contingencial (ações aleatórias da natureza e do mercado consumidor), e de assimetria de informação, desconhecimento por um tomador de decisão das informações possuídas pelos outros agentes envolvidos na transação (Williamson, 1985).

As organizações cooperativas são especialmente sensíveis a ambientes incertos, uma vez que são vulneráveis a ações oportunistas de seus associados. Cook (1995) enfatiza a propriedade comum como um dos principais problemas de agência a que estão sujeitas essas organizações, onde o associado utiliza benefícios da propriedade coletiva e não dá sua contrapartida, moldando o comportamento oportunista de free-rider. Assim, os mecanismos formais de coordenação, como os contratos, não garantem a fidelidade e o compromisso com a organização coletiva (Salomé-Pereira, 1998).

Como as organizações cooperativas são estruturas que não se sustentam sem o movimento das transações realizadas pelos membros cooperados, há necessidade de fidelidade dos membros em suas transações com a organização, assumindo a confiança um importante papel no mecanismo de coordenação nas relações entre as partes. 
Para desenvolver este mecanismo, as ações dos dirigentes da cooperativa devem valorizar a gestão da informação, utilizando-se de instâncias que reduzam a assimetria de informações entre a cooperativa e os membros associados, como as assembléias dos sócios, os comitês de representação, os informativos internos, sejam estes jornais ou canais virtuais de comunicação. Tais ações favoreceriam o compartilhamento de informações e conhecimentos, atuando positivamente na maximização de oportunidades (Hansen \& Morrow, 1999). Schneider (1982) enfatiza que, se a informação direcionada aos associados pelos dirigentes for muito limitada, eles tenderão a ignorar até que ponto os dirigentes realmente visam ou não à sua promoção econômica e social, abrindo os canais para o receio e a desconfiança, diminuindo o grau de adesão.

Os estudos de Wadsworth (2001) corroboram estes achados, chamando a atenção para a forte relação entre a disseminação de informações entre os associados e o sentimento de conexão com a organização, com impactos sobre o grau de fidelidade dos membros.

A teoria da agência enfatiza a tendência natural de os dirigentes, em função da posição que ocupam, deterem mais informações que os associados, cujo poder de controle se apresenta fraco. Desse modo, a assimetria de informação abre espaço para ações oportunistas, pois pressupõe que o agente pode utilizar informações em seu benefício próprio. Assim, resta, como alternativa, a observação dos resultados alcançados pelo agente (Lima, 1997).

Nessa perspectiva de análise, a importância da informação para as transações cooperativas vai além de permitir decisões de melhor qualidade, seja pela gestão da cooperativa, seja pelos associados com ela conectados. No entanto, constituise em ingrediente essencial na construção de confiança dos membros em suas transações com a organização. Mais ainda: sua essencialidade estende-se para a estruturação das relações do indivíduo com a organização, emergindo como substância vital ao posicionamento deste como ser social, produtivo e gerador de conhecimento.

\section{Enfraquecendo os Laços de Confiança}

Tendo fundamental importância na promoção do dinamismo organizacional, a confiança desponta para as organizações como elemento determinante do grau de adesão e comprometimento com os esforços empreendidos pelos pares. Em se tratando das organizações cooperativas, a confiança assume papel ainda mais importante, devido às características inerentes ao modelo cooperativo. 
A confiança, fenômeno estudado por vários pesquisadores, tem recebido várias classificações, como: confiança contratual, confiança baseada na competência e confiança baseada na boa vontade (Sako, 1997). Há ainda a vertente que classifica a confiança baseada no cálculo, no conhecimento (cognitiva) ou na identificação (Kramer, 1999), como pode ser encontrado em Mariz (2002). Todavia, embora haja diversos posicionamentos acerca da compreensão deste fenômeno, o ponto em comum reside em reconhecer a confiança como "questão chave nos relacionamentos dentro e particularmente entre as organizações" (Bachmann [n.d.]).

Admite-se como fundamental para o processo de construção de confiança que todas as partes envolvidas participem do diálogo de forma igual, com liberdade para representar seus interesses e participarem de diálogo franco e aberto, desprovido de manipulação, coerção e agenda oculta (Hardy, Phillips, \& Lawrence, 2003). Lorenzen (1998) argumenta que, quando os agentes, trocando informação, cooperam em direção a metas comuns, conhecendo bem um ao outro, eles constroem confiança. Esse processo verifica-se igualmente no âmbito da difusão de estratégias, elevando a segurança em trocas específicas. (Jones, Hesterly, \& Borgatti, 1997).

Tratando-se das organizações cooperativas, a informação direcionada ao associado toma ainda mais relevância, uma vez que este constitui o ativo mais específico da organização (Zylbersztajn, 2002). Evidencia-se, assim, a necessidade de buscar-se sempre ampliar a ligação desses associados com as atividades da organização (Spear, 2000), de modo a realimentar confiança e conseqüentemente o aumento das transações.

\section{Perspectiva Metodológica}

Para a concretização dos objetivos propostos neste estudo, procedeu-se a uma pesquisa qualitativa por fornecer melhor adequação ao fenômeno observado. Como objeto a ser estudado, optou-se por um estudo de caso centrado em uma cooperativa de cafeicultores localizada no Sul de Minas Gerais.

A cooperativa investigada é constituída por um quadro de mais de quatro mil associados, em sua maioria pequenos produtores, dispersos por aproximadamente sessenta municípios do Estado de Minas Gerais, com predomínio da maioria na região Sul do Estado. Por questões de viabilização da pesquisa, optou-se por investigar apenas associados da cidade sede da cooperativa.

É importante considerar a existência na cidade de outra cooperativa concorrente, como também de cinco cooperativas concorrentes localizadas em seu entorno. 
Ressalta-se que a cooperativa concorrente localizada na cidade reserva para si a comercialização de café de grandes produtores.

Na composição do estudo, foram selecionados dois grupos de análise. Um grupo composto por quatro dirigentes e outro composto por 15 associados, sendo cinco de cada categoria, segundo o volume de produção de café: pequenos, até 500 sacas; médios, 501 - 3000 sacas; e grandes produtores, acima de 3000 sacas. Buscou-se a formação de grupos heterogêneos, compostos por homens e mulheres, mais jovens e menos jovens, com o mínimo de seis anos de associação à cooperativa, dado o fato de ser o menor tempo de permanência em cargos de direção dentre os dirigentes entrevistados.

O levantamento dos dados, realizado no período de setembro a outubro de 2002, buscou a convergência de várias fontes de evidências, sendo selecionadas entrevistas semi-estruturadas (gravadas mediante prévia autorização dos entrevistados), análise de documentos (jornal da cooperativa, estatuto da cooperativa, atas de assembléias), registros em arquivos (registros de produção de café entregue pelos associados no período de 1998 a 2002) e a observação não-participante.

Para a análise da assimetria de informação e da confiança existente nas relações entre associados e dirigentes da organização, empreendeu-se a análise de conteúdo, seguindo a abordagem qualitativa. Como enfatiza Bardin (1977), a importância da análise qualitativa está no fato de a inferência ser fundada na presença do índice (tema, palavra, personagem etc.) e não sobre a freqüência da sua aparição em cada comunicação individual. Desta forma, busca-se não somente uma leitura 'da letra', mas, antes, o realçar de um sentido que se encontra em segundo plano.

Nesta perspectiva, buscou-se captar as significações da assimetria de informação e confiança por meio de conhecimentos, percepções e satisfações dos sujeitos investigados quanto ao gerenciamento de informações categorizadas, tanto internas quanto externas à organização, como também pelas dissonâncias observadas nos relatos entre associados e dirigentes. Como pano de fundo da análise, consideraram-se as informações registradas pela análise documental, sobretudo as referentes ao movimento de transações de comercialização dos membros com a organização, importante sinalizador de confiança dos membros na organização e sua gestão, como também as informações obtidas pelas entrevistas de foco conduzidas junto a funcionários ligados à área de processamento de dados e assessoria de comunicação. 


\section{Modelo de Classificação da Informação Aplicado às Organizações Cooperativas}

Para a melhor localização das assimetrias informacionais e visando favorecer a análise, construiu-se, durante a pesquisa, uma classificação da informação segundo a sua importância para os membros associados, partindo do pressuposto da relevância do associado como investidor e mantenedor das transações realizadas pela organização e, portanto, como definidor das suas necessidades informacionais.

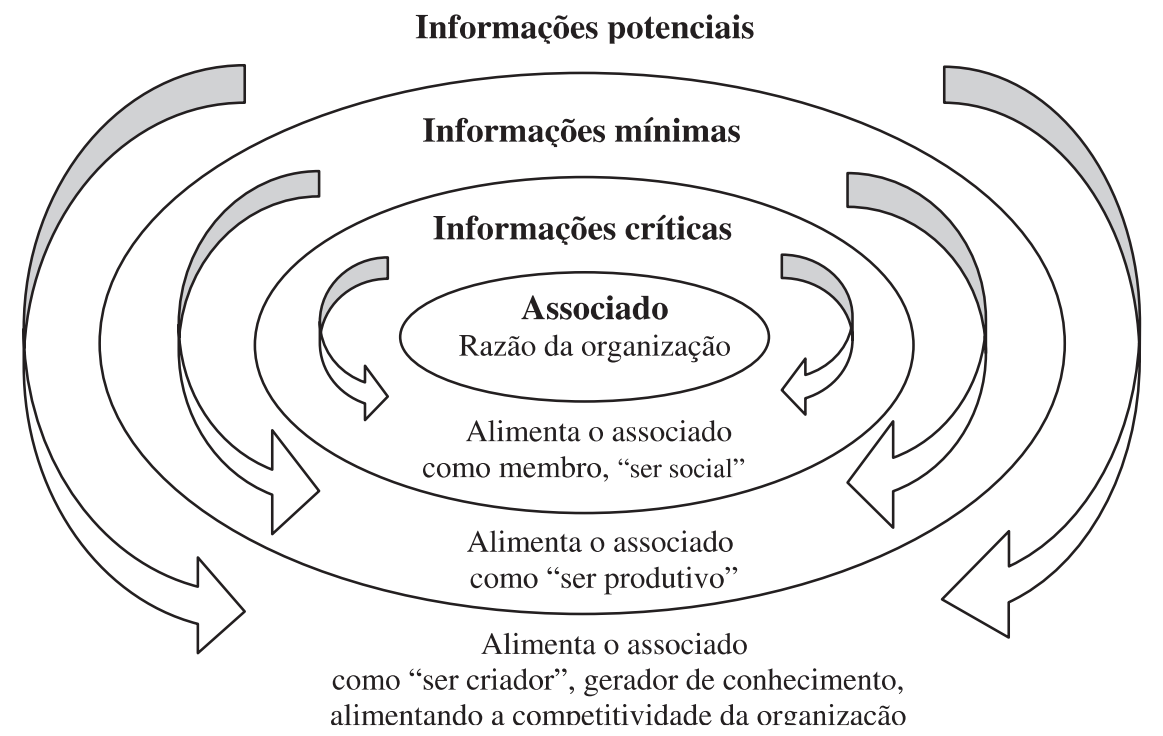

Fonte: formulado pela autora a partir de Amaral (1994).

As informações analisadas na cooperativa estudada foram segmentadas em informações internas e externas e classificadas em informações críticas, informações mínimas e informações potenciais. Como informações críticas, consideram-se as informações internas à organização, relacionadas à sua natureza estrutural e social. Por exemplo: as informações de planejamento organizacional, de comercialização, movimentações financeiras e atuação dos gestores.

A cooperativa, como organização social, tem como uma de suas responsabilidades oferecer aos membros associados informações mínimas, tais como o conhecimento dos aspectos tecnológicos básicos, difundidos por meio de palestras, cursos, dias de campo, ou provendo uma estrutura de apoio a suas necessidades.

No que tange às informações potenciais, a consideração de potencialidade 
atribuída à informação advém da visualização desta como geradora de conhecimento, criadora de valor. É o caso das informações externas à organização, que contribuam para a obtenção de melhores posicionamentos do associado, sobretudo em termos de agregação de valor nos processos comerciais. Podem ser consideradas informações potenciais aquelas mercadológicas, institucionais (incluindo ações da cadeia produtiva), econômicas, políticas e tecnológicas.

\section{Assimetria de Informações e a Confiança dos Associados na CoOperativa}

\section{A Problemática da Assimetria de Informações}

\section{Assimetria nas Informações Internas}

As informações internas à organização analisadas no estudo foram as de planejamento, comercialização, movimentação financeira, atuação dos dirigentes e atuação do Conselho Fiscal, constatando-se elevado nível de assimetria informacional.

No que se refere às informações de planejamento da organização, verificou-se a necessidade, exposta pelos associados, especialmente pequenos e médios, em obter informações mais detalhadas sobre os planos da organização. $O$ fato de os dirigentes fornecerem informações referentes às ações quando já concretizadas justifica a necessidade dos associados pela busca de informações de planejamento e não somente das decisões já tomadas, que são, segundo os dirigentes, as informações internas mais transmitidas aos associados, fato não constatado junto aos meios de informação.

“(...) o planejamento é só entre eles. A maioria não é falado na assembléia” (Associado).

Na visão dos dirigentes, a participação dos associados na elaboração dos planos da organização dá-se por meio da representatividade do conselho de administração, eleito pelos associados para gerir a organização. Evidencia-se, assim, a crença de que ao associado não cabe planejar, uma vez que ele elegeu pessoas aptas a fazê-lo.

“(...) ele participa, assim, representado pelo conselho de administração. Mas ele diretamente não. Poderá participar, mas muito esporadicamente, tipo chegar, dar uma sugestão" (Diretor). 
Cabe observar que a participação dos associados nas assembléias não recebe a devida atenção dos dirigentes no que se refere à sua importância no planejamento da organização, visto que o curto período de duração (25 minutos) para a aprovação de investimentos, a forma superficial com que as informações são apresentadas aos associados e a falta de estímulo à participação destes no debate das idéias, evidenciam a pré-formatação em que se efetivam as assembléias, constituindo-se em instâncias fortalecedoras de assimetrias informacionais.

Outro ponto a ser considerado refere-se ao medo que os associados têm em expressar-se, o que se apresenta como indicador do despreparo do quadro associativo em participar com sua voz nas decisões da organização. Ao ser questionado sobre o porquê da não-manifestação de suas dúvidas durante a assembléia, foi possível perceber o sentimento de inferioridade presente no associado com relação às suas habilidades comunicacionais, o que agrava a assimetria de informações.

“(...) faltou dizer se a cooperativa tem esse dinheiro. Como é que ela vai pagar isso?

(...) a gente não sabe falar direito. O outro lá engasgou, você viu?” (Associado).

Com relação às informações de comercialização, constatou-se que há o desejo expresso pelos associados de conhecimento das empresas com as quais a cooperativa comercializa. Observa-se a desconfiança implícita no que se refere ao resultado da comercialização.

“(...) eu tenho uma carência de informação, que firma está comprando o meu café e por quanto. Eu gostaria de saber por que eu fico sabendo aqui o preço que eu vou receber" (Associado).

“(...) no meu ponto de vista, eu acho que existe distorção, porque ela não fala pra quem que ela vende o café nosso” (Associado).

A esse respeito, constatou-se que os dirigentes desconsideram o desejo dos associados em obter tais informações, sobretudo para que empresas se efetivam as transações. A ausência dessas informações é atribuída à confiança dos associados nas ações da diretoria.

“(...) ele sabe, não tem necessidade de informar. Um negócio que eles [os associados] confiam em nós (...) o associado não quer esta informação, ele quer o dinheiro dele” (Diretor).

Tratando-se das informações financeiras, constatou-se o desejo de os associados obterem informações da situação financeira da cooperativa e da atuação da diretoria. $\mathrm{O}$ maior conhecimento dos dirigentes no que tange à situação financeira 
da organização e sua própria atuação está aliado à posição que estes ocupam como agente nas transações. Todavia a presença de assimetria pode ser verificada pelo fato de os diretores enfatizarem serem estas informações as mais transmitidas do rol de informações internas à cooperativa, o que não pôde ser verificado nos meios de comunicação utilizados e junto ao conhecimento expresso pelos associados.

As informações de atuação da diretoria são consideradas conhecidas pelos associados, evidenciando a forte presença de assimetrias. É certo que os diretores possuem mais informações de suas próprias ações. No entanto, a assimetria em relação aos associados é verificada pelo fato de estes conhecerem pouco das ações dos dirigentes, o que pode ser corroborado pelas considerações de alguns funcionários entrevistados, enfatizando que a diretoria é centralizadora, não expondo o modo como administra a organização.

“(...) eles não sabem, mas contribuiria se eles dessem mais relatórios” (Associado).

“(...) não tenho informação nenhuma. A administração é muito fechada. A administração, como se diz, é tipo ditadura. Desde quando fundou, é uma administração só, quer dizer, não tem informação quase nenhuma (...) Não tenho nada de informação de atuação da diretoria. Simplesmente estão dirigindo" (Associado).

Uma evidência da presença de assimetria nas informações internas à organização é a fraca atuação do conselho fiscal no cumprimento de seu papel de redutor e/ ou compensador de assimetrias informacionais, bem como o desejo expresso pelos associados na concretização dessas ações.

“(...) não custa pegar uma coluna do jornalzinho e falar: o conselho fiscal esclarece” (Associado).

\section{Assimetria nas Informações Externas}

Em relação às informações externas investigadas, inserem-se as informações classificadas como potenciais e mínimas, ou seja, aquelas que contribuem para a agregação de valor ao produto do associado, nos processos produtivos ou comerciais, e sua conseqüiente competitividade. Foram observadas as informações relacionadas ao conhecimento do mercado, às inovações tecnológicas, às mudanças econômicas e institucionais.

Verificou-se que os dirigentes não valorizam a transmissão de informações referentes ao mercado de insumos de interesse do produtor, não sendo também promovido o incentivo para a realização de compras nas lojas da cooperativa, deficiência de atuação que evidencia uma visão limitada dos dirigentes quanto ao papel da cooperativa como beneficiadora das economias dos associados. 
Com relação às informações de consumo, cuja transmissão é considerada irrelevante pelos diretores, verificou-se que a cooperativa não valoriza a transmissão dessas informações, seja no âmbito quantitativo, seja qualitativo, não fornecendo aos associados informações referentes às posições de oferta e demanda do café no mercado, bem como das exigências dos consumidores em níveis mundiais. Por outro lado, evidenciou-se entre os associados a importância em se obterem informações referentes às exigências dos consumidores de café, ressaltando o impacto que tal informação exerce na promoção da qualidade do produto. A não-valorização destas informações sinaliza a visão limitada dos dirigentes da cooperativa em relação aos associados.

Em sendo assim, as informações de mercado apresentaram-se como um dos pontos problemáticos na organização, havendo resistências por parte dos associados com relação à maneira como vêm sendo tratadas tais informações, sobretudo considerando que a cooperativa, mesmo possuindo interligação direta com as Bolsas de Nova Iorque e Londres, promove a centralização de tais informações na diretoria e na gerência comercial.

“(...) por incrível que pareça, eu busco informações numa outra cooperativa, eles são mais abertos; (...) Se eu precisar de uma informação agora, se eu for negociar um café, quero ver como está a Bolsa, eu tenho que ligar lá na outra cooperativa, porque eles não dão esta informação" (Associado).

“(...) olha, o mercado caiu, o mercado subiu; se você quiser saber disso, você tem que perguntar a um diretor, ou funcionário a toda a hora, até o ponto que ele vai ficar irritado e vai te colocar pra fora" (Associado).

No que se refere às informações tecnológicas associadas à produção, a disseminação de informações pela cooperativa é vista pelo associado como deficiente, refletindo na qualidade do seu produto e, conseqüentemente, em seu valor no mercado, demonstrando, portanto, sua insatisfação com relação à prestação deste serviço pela organização.

“(...) o agrônomo tem que aguardar na fila. Quando chega a sair pra gente, já passou da hora, já é um trem que tá prejudicando muito" (Associado).

No que se refere às informações mínimas, aqui consideradas as informações técnicas básicas para uma boa gestão da unidade produtiva, verificou-se a dependência da maioria dos associados da cooperativa na aquisição destas informações e, simultaneamente, a insuficiência da estrutura dos serviços prestados pela cooperativa nesta dimensão.

A quase inexistência de eventos, como palestras, e a incapacidade de atender 
prontamente às necessidades informacionais dos produtores geram perdas aos associados e estimulam uma competição entre os produtores, passando a produzir melhor aquele que pode contratar serviços técnicos particulares, gerando assimetrias informacionais entre eles. Como exemplo, detectou-se a geração de tecnologia pelo associado, influenciando a produtividade e o autodesenvolvimento da unidade de produção.

“(...) a idéia de desenvolver um novo sistema de manejo de café no terreiro surgiu a partir de uma palestra promovida pela cooperativa sobre cafés especiais" (Associado).

Considerando o conhecimento gerado e a explicitação deste na tecnologia desenvolvida, observou-se sua colocação a serviço da comunidade de associados, gerando um novo serviço a ser prestado e nova fonte de renda para o produtor rural, pois se estabeleceram novas relações contratuais deste com seus pares. Assim, a visão limitada dos dirigentes em relação à criação de assimetrias nas informações tecnológicas, subvalorizando o associado em sua capacidade de geração de conhecimento, tende a reduzir a potencialidade de inovação e autosustentação das unidades produtivas associadas.

A disseminação de informações ligadas ao cooperativismo também encontra resistência por parte dos dirigentes. Constatou-se o deslocamento da ênfase, passando de informações relacionadas à filosofia do cooperativismo, seus princípios bem como os direitos e deveres dos associados e a importância em fazer parte de uma cooperativa, para uma pequena ênfase direcionada às ações empreendidas pelo sistema cooperativista.

“(...) na verdade, não tem muito disso de informar o associado sobre o cooperativismo" (Diretor).

Em se tratando de informações econômicas, verificou-se a não-existência daquelas referentes à movimentação econômica do país. Não consta no informativo a disseminação de resumos sobre os principais fatos da economia, sobretudo comentários a respeito das oscilações do dólar, resultados da balança comercial ou a inflação acumulada mensalmente.

Constatou-se que, na transmissão de informações institucionais, a ênfase está nas informações da legislação que regulamenta o uso dos agrotóxicos e no destaque aos projetos de lei que afetam o consumo do café. Contudo, não se valorizam informações que envolvam políticas tributárias, alíquotas de exportação, ICMS, entre outras que afetam o setor, como, por exemplo, os programas do governo de financiamentos e custeio agrícola, uma das mais desejadas pelos associados. 
É interessante observar o paradoxo existente nas inter-relações dos dirigentes com os associados. Sabe-se que as melhores transações da organização dependem das melhores decisões dos associados, pois, em tese, o produto só é colocado à venda com a autorização prévia destes. Em razão disso, o fato de os dirigentes não disponibilizarem canais abertos no interior da organização para transmitir aos associados as informações necessárias às decisões de vendas passa a ser um problema não somente para os associados isoladamente, mas para o desempenho nas transações do grupo cooperativado. Assim, a assimetria nas informações externas, em especial nas mercadológicas e de novas tecnologias, limitam a produtividade e a competitividade das unidades de produção associadas, tendendo a enfraquecer todo o conjunto ao longo do tempo.

De modo geral, relatou-se que a cooperativa não transmite quaisquer informações, o que comprova a atitude de desconfiança dos associados na gestão da organização, sobretudo em face das transações de comercialização efetivadas pelos dirigentes, bem como evidencia a visualização por eles de uma gestão centralizadora. Na concepção dos associados, obter mais informações das alterações mercadológicas, como oscilações dos preços, tendências para o consumo de café, posição da oferta e da procura e dos estoques de café em níveis mundiais, poderia gerar melhores resultados como consequiência de melhores transações. Assim, a criação e manutenção pelos dirigentes de assimetrias em informações externas, tende a enfraquecer a competitividade do grupo cooperativado.

\section{Fragilidade dos Laços de Confiança no Contexto Transacional da Cooperativa}

Constatou-se que a confiança dos membros na organização é expressa como o que determina a manutenção do relacionamento. Entretanto, ainda que no discurso dos membros tenha sido expressa a existência de confiança na administração da cooperativa, tal expressão pode ser questionada ao se considerar a insatisfação dos associados quanto às ações dos dirigentes na condução da organização, sobretudo no que diz respeito ao gerenciamento das informações, como também pelo desejo expresso em melhor conhecer as ações e os resultados empreendidos pela administração. Um subsídio que indica a fragilidade dos laços de confiança dos membros com a organização refere-se à não-efetividade no movimento das transações realizadas, como pode ser visto na Tabela 1. 


\section{Tabela 1: Movimentos da Transação de Entrega de Produção na Cooperativa (Período: de 1998 a 2002)}

\begin{tabular}{|c|c|c|c|c|c|c|c|c|}
\hline \multirow{7}{*}{$\begin{array}{l}\text { Grande } \\
\text { produtor }\end{array}$} & \multicolumn{3}{|c|}{$\begin{array}{c}\text { Associados entrevistados / } \\
\text { produção média anual (sacas } 60 \mathrm{~kg} \text { ) }\end{array}$} & \multicolumn{5}{|c|}{$\begin{array}{c}\text { Movimento de café } \\
\text { na cooperativa (em sacas de } 60 \mathrm{~kg} \text { ) }\end{array}$} \\
\hline & & & & 1998 & 1999 & 2000 & 2001 & 2002 \\
\hline & Associado 1 & 1 & 14000 & 11545 & 8517 & 9185 & 4184 & 9335 \\
\hline & Associado 2 & 1 & 6000 & 1790 & 2576 & 1974 & 2575 & 1488 \\
\hline & Associado 3 & 1 & 5000 & 466 & 1893 & 1824 & 383 & 699 \\
\hline & Associado 4 & 1 & 4000 & 798 & 341 & 661 & 517 & 823 \\
\hline & Associado 5 & 1 & 3000 & 2765 & 1858 & 3242 & 1116 & 3316 \\
\hline \multirow{5}{*}{$\begin{array}{l}\text { Médio } \\
\text { produtor }\end{array}$} & Associado 1 & 1 & 1500 & 1595 & 889 & 1919 & 241 & 805 \\
\hline & Associado 2 & 1 & 1200 & 112 & 13 & 203 & 77 & 211 \\
\hline & Associado 3 & 1 & 1000 & 1257 & 1243 & 1198 & 758 & 1513 \\
\hline & Associado 4 & 1 & 800 & 1284 & 1730 & 1278 & 822 & 1358 \\
\hline & Associado 5 & 1 & 700 & 524 & 162 & 553 & 181 & 504 \\
\hline \multirow{5}{*}{$\begin{array}{l}\text { Pequeno } \\
\text { produtor }\end{array}$} & Associado 1 & 1 & 200 & 605 & 50 & 603 & 28 & 498 \\
\hline & Associado 2 & 1 & 200 & 0 & 17 & 276 & 120 & 6 \\
\hline & Associado 3 & 1 & 160 & 188 & 116 & 289 & 45 & 248 \\
\hline & Associado 4 & 1 & 100 & 100 & 339 & 188 & 13 & 113 \\
\hline & Associado 5 & I & 90 & 131 & 71 & 130 & 33 & 68 \\
\hline \multirow{4}{*}{ Diretoria } & Diretor 1 & 1 & 800 & 649 & 491 & 853 & 154 & 673 \\
\hline & Diretor 2 & 1 & 600 & 157 & 101 & 40 & 28 & 30 \\
\hline & Diretor 3 & 1 & 500 & 613 & 164 & 405 & 40 & 773 \\
\hline & Diretor 4 & 1 & 200 & 142 & 85 & 157 & 114 & 168 \\
\hline
\end{tabular}

Fonte: dados da pesquisa, Out. 2002.

Um dos pontos relatados que elucida a problemática da assimetria de informação na organização refere-se às informações direcionadas aos associados, deixandoos demonstrarem o melhor atendimento de suas necessidades informacionais por outras organizações, ainda que eles não sejam, necessariamente, associados destas.

“(...) por incrível que pareça, eu busco informações numa outra cooperativa, eles são mais abertos; (...) Se eu precisar de uma informação agora, se eu for negociar um café, quero ver como está a Bolsa, eu tenho que ligar lá na outra cooperativa, porque eles não dão esta informação" (Associado).

“(...) lá em São Sebastião [Cooperativa de São Sebastião do Paraíso], logo que o associado chega na cooperativa, tem a Bolsa passando as informações de preços a toda a hora" (Associada).

Ao se considerar que a confiança nas organizações cooperativas é determinada, em grande parte, pela identificação dos membros com a organização (Borgen, 2001), pode-se verificar a inexistência deste tipo de confiança na organização estudada. Isto porque o grupo investigado vê a cooperativa apenas como os dirigentes, não se identificando com a forma como a organização é por estes apresentada. A valorização exacerbada do patrimônio, a não-satisfação das 
necessidades dos associados e a desmotivação destes em relação aos retornos obtidos, dados os investimentos realizados ao longo dos anos, são algumas expressões de insatisfação e conseqüente não-identificação com a direção da organização.

Todavia os diretores da cooperativa acreditam na existência de elevada confiança do associado para com a organização, enfatizando a simplicidade com que os relacionamentos são conduzidos e a política das 'portas abertas' como elementos determinantes da confiança do associado na organização.

A visão que prevalece é a de que o associado confia nas ações da diretoria e, portanto, não haveria necessidade de uma política de informação bem definida, o que de fato não foi encontrado na organização. Essa interiorização do fator confiança, tal como é percebido pelos diretores, bem como a crença de que há elevado desinteresse por parte dos associados, levam a uma administração lenta com relação ao desenvolvimento da área informacional destinada aos associados, bem como à promoção de assimetrias informacionais e, conseqüentemente, à fragilização da confiança baseada na competência dos gestores.

Constatou-se que entre os associados prevalece elevado nível de confiança nos dirigentes da cooperativa, o que se atribuiu à honestidade e à seriedade dos membros. Mas essa concepção não exime o associado de pensar em um comportamento de infidelidade para com a organização, caso lhe sejam oferecidas condições mais favoráveis para venda de sua produção de café.

Outro aspecto a ser considerado, quando se trata da confiança, refere-se ao posicionamento de que a cooperativa efetua 'negócios sem risco', sendo bastante enfatizada pelos associados a segurança passada com relação às transações efetuadas. Por meio destas considerações, observa-se que, embora o critério adotado pela cooperativa seja o de 'negócio sem risco', a observação do movimento das transações evidencia que este critério não estaria exercendo força na manutenção/elevação das transações do associado na cooperativa, não sendo, portanto, o determinante da confiança do associado em transacionar maiores volumes.

Dada a importância da confiança para as transações efetivadas, pode-se afirmar que não é a imagem de transparência, seriedade e honestidade, transmitida pelos diretores, nem o critério de 'negócio sem risco' os determinantes da confiança do associado na cooperativa e, conseqüentemente, de sua fidelização. Pode-se predizer que a razão da confiança dos associados na cooperativa para ainda transacionarem os limites por eles estabelecidos baseia-se numa perspectiva calculista, sobretudo porque se relaciona ao aspecto do cálculo da segurança econômica (para grandes produtores, a segurança está relacionada à diluição de 
riscos; para os pequenos e médios, à prestação de serviços - informações, armazenagem e comercialização).

A idéia que se discute é que o ato de confiar torna-se mais vantajoso para o associado, sobretudo pequenos e médios produtores, porque possuem menos poder de negociação e são mais dependentes da cooperativa em termos de informação e prestação de serviços. Logo, a confiança que se estabelece volta-se para uma perspectiva de cálculo, porquanto, mesmo os principais (associados) possuindo informações parciais do comportamento futuro dos agentes (diretores), preferem confiar, em função do prejuízo que teriam, caso não o fizessem. Logo, percebe-se a existência de uma 'pseudoconfiança' associada a uma relação de dependência.

Deste modo, há evidências de que a não-valorização da informação, no que tange à disseminação aberta aos associados, seja um elemento que ocasiona a perda de confiança do associado na organização, vista como sendo apenas 'os diretores', cujo comportamento em relação à gestão da informação reflete a existência de ocultamento de informações, o que é percebido pelos associados.

As evidências demonstraram que os associados valorizam a informação clara e em maior quantidade como ações que deveriam ser priorizadas no gerenciamento da informação empreendido pelos dirigentes. O fato de os associados expressarem a postura dos dirigentes de outras cooperativas com relação à disseminação e à facilidade com que se pode obter informações demonstra que o associado necessita de tal postura na organização em estudo, rejeitando, portanto, as políticas da direção quanto à gestão da informação. Isto apresenta-se como uma evidência que impulsiona o surgimento da dúvida e, assim sendo, é o suficiente para gerar desconfiança em relação ao procedimento da cooperativa, se comparada a outras. Onde estaria o problema? Por que a cooperativa não procede como outras? São questionamentos que perpassam na reflexão dos associados e, portanto, de potencial influência em seu comportamento.

Como preconizam Nilsson (2001), Hakelius (1998), entre tantos outros investigadores desta temática, a configuração de uma gestão transparente e eficiente afeta os níveis de confiança e comprometimento. No entanto as evidências demonstram a ausência de transparência nas ações da gestão, gerando nos associados sentimentos de afastamento ou falta de comprometimento com a organização, abalando suas estruturas de confiança. Acredita-se que, ao longo do tempo, tais ações tenderão a elevar-se a níveis indesejáveis para a eficácia organizacional e, por conseguinte, para a sustentabilidade de uma diversidade de unidades produtivas associadas.

A não-constatação de um quadro de ação dos dirigentes que forneça aos associados um amplo escopo do valor da informação, visando ao conhecimento, 
bem como a falta de estímulo em debater o uso da informação e a influência dos contextos ambientais em seu dinamismo, evidencia-se a construção paulatina de limitações nos conhecimentos e na forma de interpretar e avaliar a potencialidade das informações para as unidades produtivas. Nesse sentido, além das incertezas advindas de um quadro de ações aleatórias ao ambiente, ter-se-iam as incertezas associadas à complexidade informacional, sendo a ausência de tais ações um importante elemento na explicação da assimetria de informações.

As evidências têm demonstrado que a assimetria de informação presente nas inter-relações agente e principal indica a influência desta sobre as relações de confiança dos associados com os dirigentes da organização, apresentando-se como forte indício do comportamento negativo nas transações efetivadas pelos membros associados.

Constatou-se que a fonte de desconfiança dos associados na cooperativa está associada à assimetria nas informações internas (críticas), especialmente informações de comercialização, planejamento e prestação de contas. Adicionalmente, pôde-se perceber que uma das fontes potenciais de redução de transações dos associados com a cooperativa está ligada à insatisfação e à falta de informações do ambiente externo à organização, consideradas pelos associados como informações potenciais, conferindo-se especial ênfase para as informações relativas ao comportamento do mercado.

Vale ressaltar que o processo de construção de confiança preconiza a participação das partes num envolvimento de proximidade, com diálogo aberto, com liberdade de representação de interesses, em que não se tenha espaço para manipulação e ocultamento de informações (Hardy et al., 2003; Lorenzen, 1998).

No entanto parece haver incompreensão ou indiferença por parte dos agentes da organização, acerca da importância da disseminação de informações transparentes, colocando a informação em uma macrodimensão, o que significa dizer não apenas implantar sistemas tecnológicos de apoio à decisão (o que é necessário e também não foi constatado), mas entender e priorizar o atendimento das necessidades informacionais de seus membros, enfatizando o valor inerente às informações. É preciso, ainda, lançar mão de mecanismos de aproximação dos membros para a troca de informações e experiências, visando estimular o processo de inovação e autodesenvolvimento das unidades produtivas, o que, em última análise, geraria também satisfação social. Também é premente atribuir às assembléias gerais um momento ímpar de debate e clareza de atuação dos agentes, conquistando a motivação do associado em se sentir protagonista na construção e desenvolvimento do empreendimento coletivo, que também é seu, fazendo-o realmente assumir a condição de principal na relação. Trata-se de reconhecimento, por parte dos dirigentes e pelos demais associados, da riqueza 
dessa forma organizacional (Spear, 2000), conferindo-se a devida atenção aos entrelaçamentos existentes entre uma efetiva gestão da informação e a confiança como importante valor social de sustentabilidade.

\section{Considerações Finais}

As evidências demonstraram que os associados da cooperativa têm pouca e, em alguns aspectos, nenhuma informação direcionada pelos agentes da organização, configurando-se a inexistência de uma cultura de informação, agravada pela visão reducionista dos dirigentes quanto ao valor da informação para os associados. Paralelamente a isto, a insatisfação quanto às informações prestadas e a consequiente desconfiança dos associados em relação às ações dos dirigentes, explicitando a necessidade de mudança no comando da organização, são justificativas plausíveis da forte presença de assimetrias informacionais no locus organizacional cooperativo.

Os condicionantes da assimetria de informação internamente encontrados na organização, em especial os valores cristalizados e avessos a uma cultura de informação, tal como as relações de poder advindas, criam uma assimetria de informação na direção inversa a um dos pontos discutidos pela teoria da agência. Trata-se do fato de o agente não necessariamente ter mais conhecimento que o principal em função da posição que ocupa. No caso estudado, constata-se que os dirigentes alimentam as condições de manutenção da assimetria, gerando a busca de informações não supridas pelo principal, de acordo com suas necessidades, desejos e percepções. Isso pode direcioná-los a fontes de informações externas e concorrentes à organização, podendo até ser conduzido a outra cooperativa, fato que pode configurar um processo de desvinculação. Tal comportamento tende a produzir reflexos diretos nas transações efetivadas e, conseqüentemente, na competitividade do grupo cooperativado.

A assimetria de informação encontrada no espaço organizacional investigado demonstrou que, quando localizada nas informações de conhecimento organizacional, consideradas críticas, atua como potenciadora de perda de confiança dos membros nos dirigentes. Quando presente nas informações externas, informações potenciais, atua como potenciadora de perda de transações dos associados, pela necessidade de rapidez na obtenção dessas informações e mais facilidade em adquiri-las junto a outras cooperativas, concorrentes da organização.

Deve-se ressaltar que os valores e normas enraizados na cultura da organização, contrários a uma cultura informacional, tal como a consolidação de um estilo de 
gestão, que em muito se aproxima da heterogestão, são grandes desafios para que os mecanismos de controle de que dispõem os associados logrem êxito, considerando sua efetividade e transparência. Assim, a promoção da redução de assimetrias em informações mínimas operar-se-ia com mais facilidade, dado que as mudanças requeridas são de cunho estrutural, ao passo que, em se tratando da redução de assimetrias em informações potenciais ou críticas, a mudança tende a esbarrar em fatores culturais e de visão estratégica, exigindo, portanto, maiores esforços dos implementadores.

Vale observar que as raízes da confiança dos associados na cooperativa se encontram circundadas por uma perspectiva de cálculo, estando fortemente associadas a uma relação de dependência dos membros com o provimento de recursos e informações. Portanto a confiança não é originada da identificação dos membros com a organização. Tal fato implica maior vulnerabilidade da organização quanto aos comportamentos dos membros associados, e em muito agravada pela assimetria de informação encontrada no espaço organizacional. Logo, a assimetria de informação, visualizada em sua macrodimensão, tende a moldar nos membros comportamentos do tipo 'correr-sozinho', que não deveriam ser tachados de oportunistas sem maiores análises.

Sugere-se, então, que a conceituação nos relacionamentos que compõem o objeto de estudo da teoria da agência absorva, de modo mais aprofundado, outros fenômenos organizacionais, como a cultura, o poder, as formas de gestão e a complexidade cognitiva dos atores, levando-se em conta história de vida, valores, prioridades, necessidades e desejos. Assim, desloca-se de uma análise estática para um diálogo que abarque os pormenores da dinâmica dos relacionamentos.

Acredita-se que novas investigações dos aspectos cognitivo, cultural e de formas de gestão que permeiam os relacionamentos de agente-principal poderiam trazer novos enfoques sobre a problemática da assimetria informacional e seus reflexos na confiança em relacionamentos cooperativos. Assim como também às teorias da agência e dos custos de transação, tornando mais visível a influência da assimetria de informação na configuração, por exemplo, dos graus de incerteza, o que até então tem sido ofuscado pelas formulações propostas pela teoria dos custos de transação.

Fica clara também a necessidade de que novos estudos sejam conduzidos para esclarecer se as razões do 'dito oportunismo' dos associados nas cooperativas estariam ligadas a uma gestão da informação centralizada, autocrática e profundamente assimétrica, considerando-se sobretudo que, entre os determinantes ambientais da competitividade e da sustentabilidade, imperam não somente qualidade, rapidez e inovação, mas também confiança. Espera-se que outros 
pesquisadores acreditem nesta proposta e especulem novos rumos no que se reporta a esta temática.

\section{Artigo recebido em 01.11.2004. Aprovado em 29.04.2005.}

\section{ReferênCias Bibliográficas}

Amaral, L.A. M. (1994).

Praxis: um referencial para o planejamento de sistemas de informação. Tese $\mathrm{PhD}$, Universidade do Minho, Portugal.

Amodeo, N. B. P. (1999).

As cooperativas agroindustriais e os desafios da competitividade. Tese de Doutorado, Universidade Federal Rural do Rio de Janeiro, Soropédica, Rio de Janeiro, Brasil.

Bachmann, R. (n.d.).

Trust and power as means of coordinating the internal relations of the organization: a conceptual framework. Recuperado em 01 julho, 2003, de http://www.ub.rug.nl/eldoc/ som/g/02G10/02G10.pdf

Bardin, L. (1977).

Análise de Conteúdo. Lisboa: Edições 70.

Blomqvist, K., \&

Stahle, P. (2000, September).

Organizational trust building. Paper presented at the 16th, Annual IMP Conference, Bath, UK, 7th-9th. Recuperado em 20 outubro, 2002, de http://www.impgroup.org/uploads/ papers/37.pdf

Borgen, S. O. (2001).

Identification as a trust-generating mechanism in cooperatives. Annals of Public and Cooperative Economics, 72(2), 209-228.

Cook, M. (1995).

The future of U. S. agricultural cooperatives: a neo-institutional approach. American Journal of Agricultural Economics, 77(5), 11531159.

Gambetta, D. (2000).

Can we trust trust? In D. Gambetta (Ed.). Trust: making and breaking cooperative relations (Chap. 13, pp. 213-237). Oxford: Department of Sociology, University of Oxford. Recuperado em 01 maio, 2003, de http:/ /www.sociology.ox.ac.uk/papers/ gambetta213-237.pdf

Good, D. (2000).

Individuals, interpersonal relations, and trust. In D. Gambetta.(Ed.). Trust: making and breaking cooperative relations (Chap. 3, pp. 31-48). Oxford: Department of Sociology, University of Oxford. Recuperado em 01 maio, 2003, de http://www.sociology.ox.ac.uk/

Hakelius, K. (1998).

Paths of change for farmer cooperatives [Working Paper]. International Cooperatives Research Conference, Cork, Ireland. 
Hansen, M. H., \&

Morrow, J. R., Jr. (1999).

The role of trust and governance in managing farmer cooperatives: maximizing opportunities. Proccedings of the World Food and Agribusiness Congress, Florence, Italy. 9. Recuperado em 8 novembro, 2002, de http://www.ifama.org/conferences/9/ $1999 / 1999 \% 20$ Congress/ Forum\%20Papers_PROCEEDINGS/ Hansen_Mark.PDF

Hardy, C.,

Phillips, N., \&

Lawrence, T. B. (2003).

Resources, knowledge and influence: the organizational effects of the interorganization collaboration. Journal of Management Studies, 40(2), 321-347.

Jones, C.,

Hesterly, W. S., \&

Borgatti, S. P. (1997).

A general theory of network governance: exchange conditions and social mechanisms. Academy of Management Review, 22(4), 911-945.

Kramer, R. M. (1999).

Trust and distrust in organizations: emerging perspectives, enduring questions. Annual Review of Psychology, 50, 569-98.

Lima, E. C.P. (1997).

Privatização e desempenho econômico: teoria e evidência empírica (Texto para discussão, $\mathrm{n}$. 532). Brasília, DF: IPEA.

Lorenzen, M. (1998).

Information cost, learning, trust: lessons from co-operation and higherorder capabilities amongst geographically proximate firms. DRUID Sumer Conference [Working Paper, ${ }^{\circ}$ 98-21]. Copenhagen: Copenhagen Business School, Denmark. Recuperado em 15 setembro, 2002, de http:// www.druid.dk/uploads/tx_picturedb/ ds1998-24.pdf

Lorenz, E. H. (2000).

Neither friends nor strangers: informal networks of subcontracting in french industry. In D. Gambetta (Ed.). Trust: making and breaking cooperative relations. (Chap. 6, pp. 194-210). Oxford: Department of Sociology, University of Oxford. Recuperado em 01 maio, 2003, de http:// www.sociology.ox.ac.uk/papers/ lorenz194-210.pdf

Mariz, L. A. C. (2002, setembro).

Explorando os limites do conceito de confiança interorganizacional: o caso de redes de desenvolvimento tecnológico. Anais do Encontro Nacional da Associação Nacional de PósGraduação e Pesquisa em Administração, Salvador, BA, Brasil, 26.

Naves, F. L. (1999).

Práticas de gestão em organizações capitalistas e cooperativas: similaridades e contradições. Perspectiva Econômica, 34(105), 67-80.

Nilsson, J. (2001).

Organizational principles for cooperatives firms. Scandinavian Journal of Management, 17(3), 329-356.

Sako, M. (1997).

Does trust improve business performance. London: London School of economics and political science. 
Salomé-Pereira, H. M. (1998).

Direitos de propriedade em projetos cooperativos de pesquisa. Tese de Doutorado, Faculdade de Engenharia e Administração, Universidade de São Paulo, São Paulo, SP, Brasil.

Schneider, J. O. (1982).

Principais problemas na comunicação cooperativa. In D. Pinho (Ed.). Administração de cooperativas [Manual de cooperativismo] (Vol. III, pp. 141-145). São Paulo: CNPq.

Spear, R. (2000).

The cooperative advantage. Annals of Public and Cooperative Economics, 71(4), 507-523.

Wadsworth, J. (2001).

Keep the co-op candle burning Effective member relations essential to keep co-op spirit alive \& kicking. Rural Cooperatives Magazine, 68(2), 19-30.

Williamson, O. E. (1985).

The economic institutions of capitalism: firms, markets, relational contracting. New York: Free Pass.

Zuurbier, P. J. P., \&

Bremmers, H. (1997).

Analyzing farmer-coop relations: an adjusted TCE-Approach. Anais do Workshop sobre AgriChain Management. Ribeirão Preto, SP, Brasil, 1.

Zylbersztajn, D. (2002).

Quatro estratégias fundamentais para cooperativas agrícolas [Working Paper, $\mathrm{n}^{\circ}$ 02/017). Universidade de São Paulo, São Paulo, SP, Brasil. 
